\title{
Verificação de compatibilidade de parâmetros mensuráveis para aplicação do SBTool Urban em habitações de interesse social (HIS) brasileiras.
}
Verification of compatibility of measurable parameters for application of SBTool Urban in Brazilian social housing.

\section{Comprobación de compatibilidad de parámetros medibles para la aplicación SBTool Urban} en viviendas sociales brasileñas.

Djanny Klismara de Oliveira Arquitetura e Urbanismo pela Universidade de Araraquara

Érico Masiero Doutor em Engenharia Urbana (UFSCar) ericomasiero@yahoo.com.br

Thayná Verger Paulino 


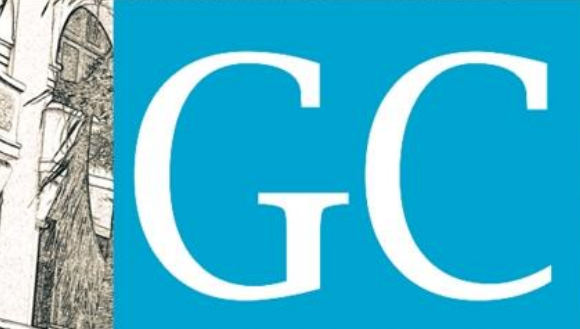

ISSN 2318-8472

v. 08, n. 55,2020

Revista Nacional de

Gerenciamento de Cidades

\section{MÉTODO}

O método foi pautado em pesquisa bibliográfica, abordagem multicritério de estudo de caso para a avaliação de empreendimentos de HIS da cidade de Catanduva, SP.

A aplicação dos procedimentos metodológicos contemplou as seguintes etapas:

- Verificação dos critérios do Selo Casa Azul analisados nos empreendimentos da cidade de Catanduva;

- Escolha e comparação dos critérios atendidos por uma referência de análise (benchmark) certificado pelo Selo Casa Azul que, para tanto, deve apresentar um perfil de maior sustentabilidade em relação aos estudos de caso. Nessa pesquisa, foi adotado como benchmark o conjunto de Edifícios E/G - Paraisópolis;

- Verificação dos indicadores do SBTool Urban com temas correspondentes aos critérios selecionados do Casa Azul (21 critérios);

- Estabelecimento do cálculo da ferramenta SBTool Urban para verificação de aplicabilidade diante das características nacionais apontadas pelo Casa Azul.

\section{RESULTADOS}

Inicialmente, foram verificados alguns critérios do Selo Casa Azul coletados em dois empreendimentos de HIS (Residencial Nova Catanduva I e Residencial Júlio Ramos) em Catanduva, São Paulo. Os critérios investigados fazem parte das categorias (1) Qualidade Urbana; (2) Eficiência Energética; e (3) Gestão de água. No total foram analisados 21 critérios.

A aplicação dos critérios do Selo Casa Azul seguiu juntamente com a observação das exigências realizadas por órgãos públicos envolvidos no processo de aprovação dos empreendimentos, e que considerassem a promoção da sustentabilidade. O check list do Selo Casa Azul está pautado na verificação de critérios existentes durante o processo de projeto e de construção, respondendo se determinado fator existe ou foi atendido no empreendimento.

Dessa forma, os empreendimentos Residencial Nova Catanduva I e Residencial Júlio Ramos atenderam, respectivamente, a 16 e 12 critérios.

\subsection{Apresentação do benchmark - Edifícios G/E Paraisópolis}

Em uma segunda etapa, conforme as fichas de análise dos Edifícios E/G já certificados em nível Ouro pelo Selo Casa Azul e por informações disponibilizadas pelo escritório Elito Arquitetos Associados (2008), foram verificados os critérios das mesmas categorias. A referência em questão atendeu a 18 critérios, justificando sua escolha como benchmark e possibilitando a sequência de análise que inclui os cálculos propostos pelo SBTool Urban. A escolha pelos Edifícios E/G - Paraisópolis considerou o fato do empreendimento ser certificado em nível Ouro pelo Casa Azul e se tratar de habitações de interesse social. Outra questão foi o desempenho superior em relação aos empreendimentos de Catanduva quando considerados os mesmos critérios de avaliação.

\subsection{Associação dos critérios do Selo Casa Azul $x$ indicadores SBTool Urban}

Essa etapa compreendeu o estabelecimento dos assuntos relacionados em ambas as ferramentas. Para tanto, foi realizado um cruzamento dos critérios do Selo Casa Azul com os indicadores do SBTool Urban por 


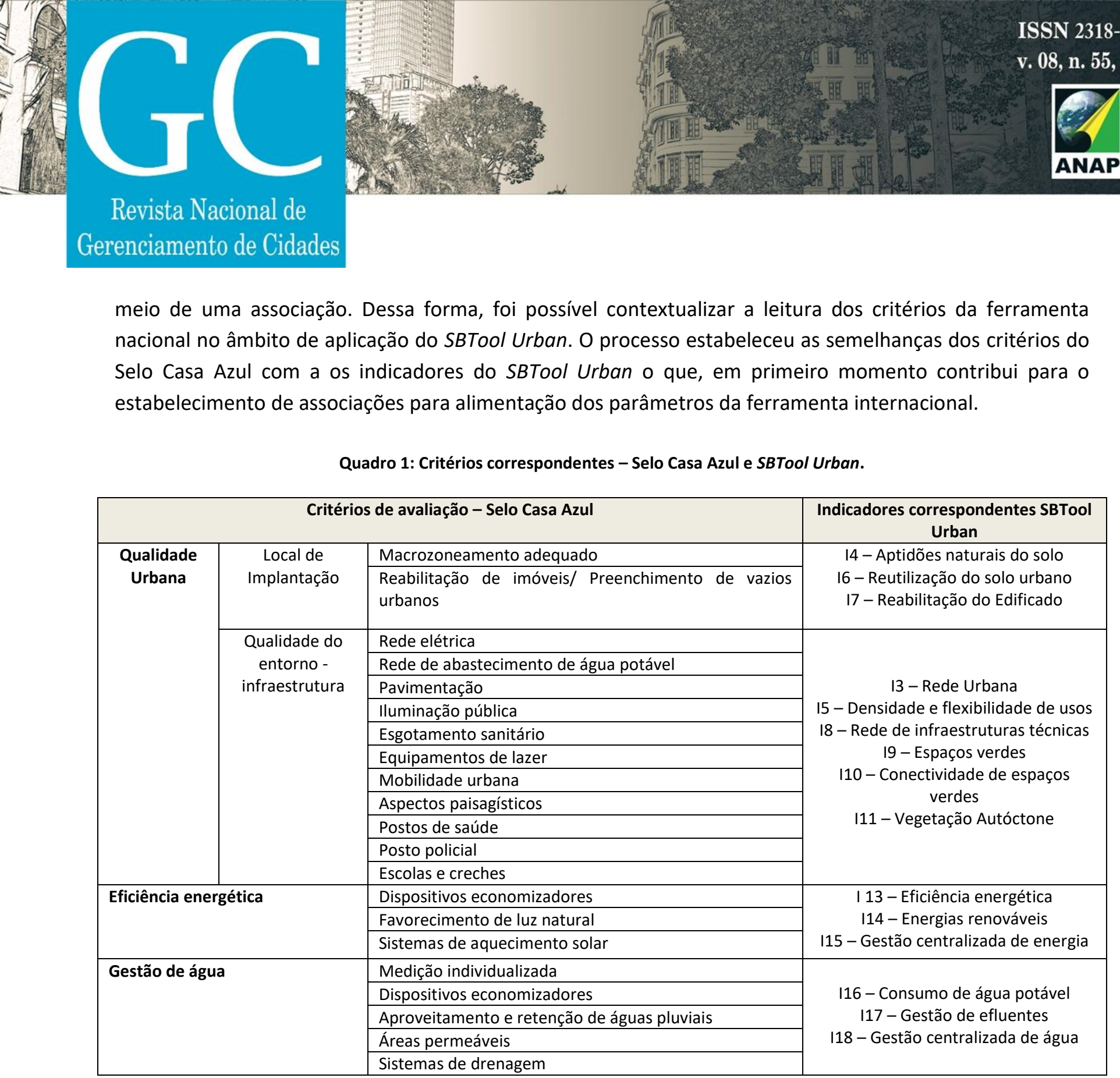

nacional no âmbito de aplicação do SBTool Urban. O processo estabeleceu as semelhanças dos critérios do Selo Casa Azul com a os indicadores do SBTool Urban o que, em primeiro momento contribui para o estabelecimento de associações para alimentação dos parâmetros da ferramenta internacional.

Quadro 1: Critérios correspondentes - Selo Casa Azul e SBTool Urban.

Fonte: Autores (2019)

\subsection{Cruzamento com os cálculos do SBTool Urban}

A estrutura do SBTool Urban traz como procedimento de análise o cálculo do valor de cada indicador individualmente. O processo compreende duas etapas: uma de normalização e a segunda de ponderação (BRAGANÇA, 2017, p. 3197). A etapa de normalização é responsável pela padronização da leitura do indicador por meio da tradução do valor para uma escala entre 0 e 1. Essa primeira fase tem por objetivo acabar com problemas referentes à compreensão de escala na leitura dos dados tais como "quanto maior menor" ou "quanto menor melhor", evitando problemas sobre a compreensão do seu efeito de escala. Já a segunda etapa, compreende o cálculo referente ao peso atribuído a cada indicador conforme o grau de influência na leitura dos impactos identificados. Por meio do processo de ponderação é possível flexibilizar a análise de acordo com as características locais. Assim, o processo de avaliação é composto por: (1) avaliação individual dos indicadores; (2) normalização dos valores coletados mediante adoção de uma referência de sustentabilidade e score dos valores trazidos pela metodologia internacional SBTool e; (3) ponderação dos valores e cálculo final com o respectivo peso. 


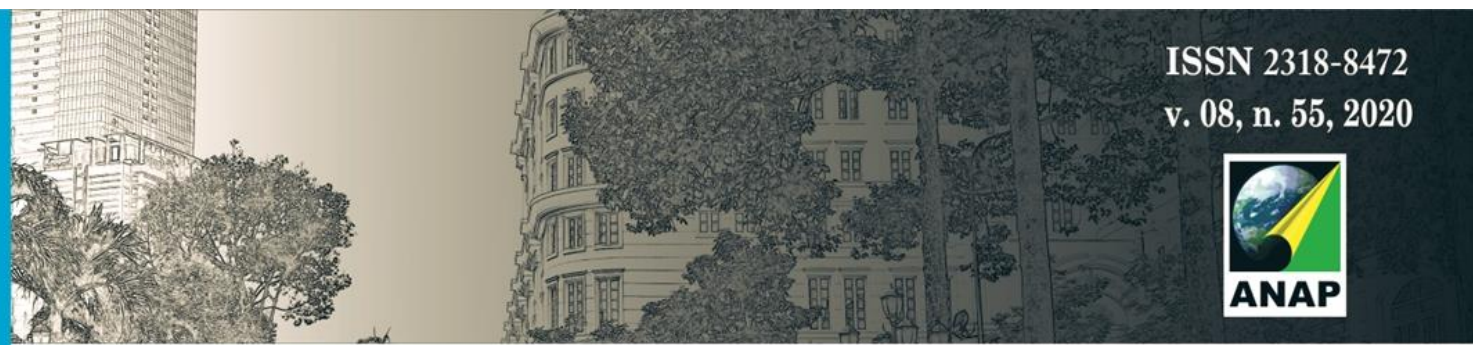

Revista Nacional de

Gerenciamento de Cidades

Posteriormente a verificação dos dados dos empreendimentos em Catanduva e da verificação do benchmark, foram realizados ensaios de aplicação de alguns dos indicadores de acordo com a ferramenta SBTool Urban para a mensuração do potencial sustentável identificado incialmente pelo Casa Azul.

Considerando a forma como foi organizada a coleta de dados dos critérios do Selo Casa Azul, a avaliação do cálculo procurou abranger as categorias ao invés dos indicadores individualmente, visto que a presente pesquisa não foi a fundo na investigação minuciosa dos projetos referentes aos sistemas dos empreendimentos. Outra consideração foi o fato de que os critérios utilizados correspondem a mais de um indicador do SBTool Urban, o que inviabiliza o cálculo individual nesse caso. Assim foram considerados os tópicos de análise da seguinte forma: (1) Qualidade urbana; (2) Eficiência energética e; (3) Gestão de água. No quadro a seguir, é possível visualizar os valores atribuídos aos empreendimentos por ambas as ferramentas, sendo que os valores referentes ao SBTool Urban são interpretados como "mais sustentáveis" a medida que se aproximam de 1 e demonstram um potencial de "o mais sustentável" quando são superiores a 1.

Quadro 2: Visão geral dos levantamentos e cálculos.

\begin{tabular}{|l|c|c|c|c|}
\hline \multicolumn{1}{|c|}{ Categorias } & \multicolumn{2}{c|}{$\begin{array}{c}\text { Scores - Residencial } \\
\text { Nova Catanduva I }\end{array}$} & \multicolumn{2}{c|}{$\begin{array}{c}\text { Scores - Residencial Júlio } \\
\text { Ramos }\end{array}$} \\
\hline & C. Azul & SB. Urban & C. Azul & SB. Urban \\
\hline Qualidade Urbana (13 critérios) & 11 & 1,18 & 8 & 0,74 \\
\hline Eficiência Energética (3 critérios) & 5 & 1,06 & 3 & 0,73 \\
\hline Gestão da água (5 critérios) & 3 & 0,78 & 3 & 0,78 \\
\hline
\end{tabular}

\section{CONCLUSÃO}

Em primeiro momento, foi possível verificar que a associação dos métodos e a definição da compatibilidade dos parâmetros e indicadores, considerando suas características originais, são possíveis de serem realizadas. Os levantamentos em ambas as ferramentas ainda possibilitaram a associação entre as diferentes leituras da sustentabilidade em relação ao olhar voltado para o edifício e ao ambiente urbano de uma maneira mais ampla, visto que, apesar das similaridades entre os critérios e indicadores, as ferramentas apresentam focos de análise específicos.

A possibilidade de estabelecimento de referências para uma análise qualitativa também contribui para um processo ascendente do potencial de sustentabilidade do espaço construído ou região analisada, pois estabelece metas com maior legitimidade considerando a adoção flexível de benchmarks que pode também, ser realizada de maneira frequente no decorrer da vida útil das edificações. Assim, a análise qualitativa dos empreendimentos contribui para a ampliação da discussão dos resultados e insere uma classificação do nível de sustentabilidade alcançado, além do número de itens atendidos verificados. 
